\title{
Retrospective analysis of patients self-referred to comprehensive ophthalmology seeking second opinions
}

This article was published in the following Dove Press journal:

Clinical Ophthalmology

10 June 2013

Number of times this article has been viewed

\author{
Daniel Gologorsky' \\ Scott H Greenstein ${ }^{2}$ \\ 'Dartmouth Medical School, \\ Hanover, NH, USA; ${ }^{2}$ Department \\ of Ophthalmology, Massachusetts Eye \\ and Ear Infirmary, Harvard Medical \\ School, Boston, MA, USA
}

\begin{abstract}
Patients choose to seek a second opinion in matters related to their health for a variety of reasons, and the total cost associated with these second opinion visits is estimated to be billions of dollars annually. Understanding the reasons behind second opinion self-referrals is key to improving patient satisfaction and reducing redundancy in delivered health care. This study represents a retrospective analysis of the records from a single provider at the Massachusetts Eye and Ear Infirmary (MEEI) Comprehensive Ophthalmology Service in order to determine the various reasons that patients self-refer to an ophthalmology clinic seeking second opinions. A total of 174 patients presenting for a second opinion were identified over a one-year period. Patients presented for second opinions for two primary reasons: $60 \%$ presented in order to seek a confirmation of a diagnosis from an outside ophthalmologist (54\%) or optometrist (6\%), and $40 \%$ presented due to a previous adverse experience with an outside provider, such as perceived treatment failure $(26 \%)$, poor bedside manner $(3 \%)$, distrust of the provider $(5 \%)$, and poor provider communication skills $(7 \%)$. This study strives to reiterate that the reduction of adverse patient experiences through effective communication of expected treatment options and outcomes, with a realistic time course of therapy, could significantly improve patient satisfaction and reduce costly second opinion visits.
\end{abstract}

Keywords: referral, self-referral, second opinion, comprehensive ophthalmology

\section{Introduction}

There are many reasons why patients choose to seek a second opinion in matters related to their health. Across many medical specialties, these reasons include, but are not limited to, a desire for reassurance and independent corroboration about the accuracy of a diagnosis, an elaboration of potential treatment options, dissatisfaction with a previous physician encounter, or an insurance requirement prior to an invasive procedure. ${ }^{1-3}$ The total cost associated with these second opinion visits is estimated to be billions of dollars annually, with profound economic implications for patients and the health care system. ${ }^{4}$

Understanding the reasons behind second opinion self-referrals is key to improving patient satisfaction and reducing redundancy in delivered health care. ${ }^{5,6}$ This topic has received relatively little attention in English language literature, with few studies tabulating specific reasons for second opinions and none focusing on ophthalmology. The authors of this report review the reasons that patients seeking second opinions self-refer to the comprehensive ophthalmology clinic at the Massachusetts Eye and Ear Infirmary (Boston, MA, USA).
Correspondence: Scott H Greenstein Department of Ophthalmology, Massachusetts Eye and Ear Infirmary, Harvard Medical School, 243 Charles Street, Boston, MA, 02II4, USA

Tel +l 6175237900

Email scott_greenstein@meei.harvard.edu 


\section{Methods}

Approval was obtained from the Institutional Review Board at the Massachusetts Eye and Ear Infirmary (MEEI) to access the records of all patients presenting to a single provider at the Comprehensive Ophthalmology Service from October 1, 2011 through September 30, 2012. The Comprehensive Ophthalmology Service provides primary eye care and cataract surgery for patients at MEEI. This study represents a retrospective analysis of the records of 174 patients seeking a second opinion that were identified over the indicated time period that had self-referred to a single provider, MEEI Comprehensive Ophthalmology Service.

\section{Results}

A total of 174 patients were identified from a pool of 6398 individuals presenting to the comprehensive ophthalmology clinic of one attending physician at the MEEI. Of these, 74 (43\%) were male and $100(57 \%)$ were female. The patients ranged in age from 18-95 years, with a mean age of 60.94 years.

Patients presented to the comprehensive service for a second opinion for a wide variety of reasons, summarized in Table 1. These reasons were organized into categories. The two principle categories of referral were patients seeking a confirmation of diagnosis, or those who had suffered an adverse experience.

In the category of "patients seeking a diagnosis confirmation", patients presented as self-referrals from either an outside ophthalmologist or an outside optometrist. In either case, a confirmation of diagnosis was invariably coupled with a request for more information about their condition. Sixty percent of the 174 self-referral patients came for this reason, with 54\% coming from outside ophthalmologists and $6 \%$ from outside optometrists.

In the "adverse experience with an outside provider" category, patients presented as self-referrals for a variety of

Table I Retrospective analysis of the reasons patients present as self-referrals for second opinions*

\begin{tabular}{lll}
\hline Requests confirmation of diagnosis/more information & $\mathbf{1 0 4}$ & $\mathbf{6 0 \%}$ \\
From outside ophthalmologist (MD) & 94 & $54 \%$ \\
From outside optometrist (OD) & 10 & $6 \%$ \\
Previous adverse experience & $\mathbf{7 0}$ & $\mathbf{4 0 \%}$ \\
Poor bedside manner & 5 & $3 \%$ \\
Distrust of provider & 8 & $5 \%$ \\
Perceived treatment failure/complications & 45 & $26 \%$ \\
Poor provider communication & 12 & $7 \%$ \\
Total & $\mathbf{1 7 4}$ & $\mathbf{1 0 0 \%}$ \\
\hline
\end{tabular}

Note: *All values are rounded to the nearest whole number. reasons, all related to an adverse experience with an outside medical provider. These reasons included perceived treatment failure (26\%), poor bedside manner (3\%), distrust of the provider (5\%), and poor provider communication skills (7\%). Cumulatively, $40 \%$ of all self-referrals presented due to an adverse experience.

\section{Discussion}

This retrospective study analyzes and categorizes the various reasons patients seek a second opinion as self-referrals at a single comprehensive ophthalmology clinic. A full $60 \%$ of patients seek a confirmation of diagnosis and more information about their disorder, while $40 \%$ present due to an adverse experience with an outside provider. Similar studies in oncology, neurological surgery, and orthopedic surgery confirm these two categories as very common reasons for a second opinion. ${ }^{7-11}$

Adverse experiences are often confounded with one another. We implemented a categorization scheme in order to better appreciate the major reasons for a self-referral. Nonetheless, confounding remains a challenge. For example, one patient described how her outside ophthalmologist "promised perfect vision" after cataract surgery. After the procedure, however, the patient was disappointed that her uncorrected distance vision was poorer than her near vision, though the patient's distance vision corrected to 20/20. Interpreting the primary reason for a visit is often difficult in that it often involves more than one category of adverse experience. In this example, the patient sought a second opinion because she perceived her treatment as a failure, though poor communication on the part of her ophthalmologist in setting realistic expectations was also an issue.

This study is important in that it has significant ramifications. First, improved access to information through the Internet has resulted in more knowledgeable patients who are often more skeptical of a single medical authority, and are taking a more active role in their health care decisions. ${ }^{3,12}$ This is evidenced by the large number of patients seeking second or even third opinions from both optometrists and medical doctors; in our study, a full $60 \%$ of self-referrals present with the purpose of a confirmation of a diagnosis with a goal of attaining further information on the disease entity. Most patients have Internet access; per one survey, $83 \%$ of patients expressed interest in having their physicians provide them with links to reputable websites to improve their health care knowledge of their disease entities. ${ }^{13}$ 
Second, as the remaining $40 \%$ of all second opinion self-referrals are due to previous adverse experiences, a reduction of these unfavorable encounters should significantly reduce redundant visits, patient attrition to other providers, and associated health care costs. ${ }^{6}$ The four principle categories of adverse experiences included perceived treatment failure $(26 \%)$, poor bedside manner $(3 \%)$, distrust of the provider (5\%), and poor provider communication skills (7\%). In our study, patients most often perceived treatment failure in chronic conditions, such as dry eye syndrome. In many of these cases, physicians did not take time to establish realistic treatment expectations or therapy time-courses with their patients, often resulting in a perceived treatment failure. Poor bedside manner was rarely the principle reason for self-referred patients. One notable example was that of an elderly patient presenting to an outside ophthalmologist with a chief complaint of new floaters; the physician abruptly replied, "they are nothing, and you're not due here for another 6 months." Distrust of the provider was demonstrated most frequently in patients that felt pushed into undergoing a surgical procedure. One particular patient complaining of "mildly blurry vision" was told by two outside providers that she needed cataract surgery, despite having vision correctable to $20 / 25$ in each eye. Many such patients, distrustful of their first provider, felt that the natural history of their respective conditions was never properly explained to them, and that they were not presented with treatment alternatives. Finally, improved provider communication skills can further reduce self-referrals to outside providers. Aside from improving physicianpatient relationships, enhanced communication skills can further reduce the potential for litigation when it comes to adverse outcomes. ${ }^{14}$ Ultimately, this study strives to reiterate that the reduction of adverse patient experiences through effective communication of expected treatment options and outcomes, with a realistic time course of therapy, could significantly improve patient satisfaction and reduce costly second opinion visits.

This study has several important limitations. First, the analysis is retrospective in nature, and the lack of an interview setting is a significant disadvantage in a project determining the reasons patients seek a second opinion. Second, many of the patient histories and chief complaints are electronically entered by technicians, often brief, and leave out important historical data. More thorough and consistent methods for data collection and input could obviate sampling biases and lead to more rigorous and generalizable conclusions. Third, though we maintain that the conclusions of this study can be applied across a variety of ophthalmology practices, we recognize that the subset of patients seeking a second opinion at MEEI may not necessarily be representative of the general population or of other academic departments. Fourth, many patients present for a second opinion for more than one reason, and categorizing the chief reason for self-referral relies heavily on the subjective interpretation of the reviewer. A future study should rely more heavily on patient interviews, demand more consistent and rigorous methods of data gathering, include more patients from more than one provider, and undergo multiple independent chart reviewers.

\section{Disclosure}

The authors report no conflicts of interest in this work.

\section{References}

1. Axon A, Hassan M, Niv Y, Beglinger C, Rokkas T. Ethical and legal implications in seeking and providing a second medical opinion. Digestive Diseases. 2008;26(1):11-17.

2. Vashitz G, Davidovitch N, Pliskin JS. Second medical opinions. Harefuah. 2011;150(2):105-110.

3. Moumjid N, Gafni A, Bremond A, Carrere MO. Seeking a second opinion: do patients need a second opinion when practice guidelines exist? Health Policy. 2007;80(1):43-50.

4. Wagner TH, Wagner LS. Who gets second opinions? Health Affairs. 1999;18(5):137-145.

5. Greenfield G, Pliskin JS, Feder-Bubis P, Wientroub S, Davidovitch N. Patient-physician relationships in second opinion encounters - the physicians' perspective. Social Science and Medicine. 2012;75(7): 1202-1212.

6. Mellink WA, DulmenAM, Wiggers T, Spreeuwenberg PM,EggermontAM, Bensing JM. Cancer patients seeking a second surgical opinion: results of a study on motives, needs, and expectations. Journal of Clinical Oncology. 2003;21(8):1492-1497.

7. van Dalen I, Groothoff J, Stewart R, Spreeuwenberg P, Groenewegen P, van Horn J. Motives for seeking a second opinion in orthopaedic surgery. Jof Health Serv ResPolicy. 2001;6(4):195-201.

8. Tattersall MH, Dear RF, Jansen J, et al. Second opinions in oncology: the experiences of patients attending the Sydney Cancer Centre. Med J Aust. 2009;191(4):209-212.

9. Wijers D, Wieske L, Vergouwen MD, Richard E, Stam J, Smets EM. Patient satisfaction in neurological second opinions and tertiary referrals. J Neurol. 2010;257(11):1869-1874.

10. Gamache FW. The value of "another" opinion for spinal surgery: A prospective 14-month study of one surgeon's experience. Surg Neurol Int. 2012;3(Supp1 5):S350-S354.

11. Oskay-Ozcelik G, Lehmacher W, Konsgen D, et al. Breast cancer patients' expectations in respect of the physician-patient relationship and treatment management results of a survey of 617 patients. Ann Oncol. 2007;18(3):479-484.

12. Greenfield G, Pliskin JS, Wientroub S, Davidovitch N. Orthopedic surgeons' and neurologists' attitudes towards second opinions in the Israeli health care system: a qualitative study. Israel Journal of Health Policy Research. 2012;1(1):30.

13. Narendran N, Amissah-Arthur K, Groppe M, Scotcher S. Internet use by ophthalmology patients. Br J Ophthalmol. Mar 2010;94(3): 378-379.

14. Levinson W. Physician-patient communication: a key to malpractice prevention. JAMA. 1994;273:1619-1620. 


\section{Publish your work in this journal}

Clinical Ophthalmology is an international, peer-reviewed journal covering all subspecialties within ophthalmology. Key topics include: Optometry; Visual science; Pharmacology and drug therapy in eye diseases; Basic Sciences; Primary and Secondary eye care; Patient Safety and Quality of Care Improvements. This journal is indexed on

Submit your manuscript here: http://www.dovepress.com/clinical-ophthalmology-journal
PubMed Central and CAS, and is the official journal of The Society of Clinical Ophthalmology (SCO). The manuscript management system is completely online and includes a very quick and fair peer-review system, which is all easy to use. Visit http://www.dovepress.com/ testimonials.php to read real quotes from published authors. 